\title{
Effects of Acetate-Free Citrate Dialysate on Glycoxidation and Lipid Peroxidation Products in Hemodialysis Patients
}

\author{
Atsumi Masuda Shinji Hagiwara Mitsuo Tanimoto \\ Fumiko Kodama Kozue Okumura Nao Nohara \\ Mayumi Matsumoto Masayuki Maiguma Keisuke Omote \\ Hiroaki lo Atsushi Kurusu Isao Ohsawa Yoshio Shimizu \\ Chieko Hamada Satoshi Horikoshi Yasuhiko Tomino
}

Division of Nephrology, Department of Internal Medicine, Juntendo University Faculty of

Medicine, Tokyo, Japan

\section{Key Words}

Acetate-free dialysate $\cdot$ Pentosidine $\cdot$ Malondialdehyde-modified low-density lipoprotein •

Hemodialysis • Atherosclerosis

\begin{abstract}
Background/Aims: Previous studies have shown the presence of high levels of glycoxidation and lipid peroxidation products in association with atherosclerosis in patients with end-stage kidney disease. Acetates are commonly used buffer for correcting metabolic acidosis in hemodialysis (HD) patients. Since the toxic effects of acetates are well established, acetate-free citrate dialysate (AFD) has become available in Japan. The objective of the present study was to evaluate the suppressive effects of AFD on oxidative stress in maintenance HD patients by measuring plasma pentosidine and malondialdehyde-modified low-density lipoprotein (MDA-LDL) levels as markers for glycoxidation and lipid peroxidation products. Methods: Plasma pentosidine, MDA-LDL and other laboratory parameters were examined on maintenance $\mathrm{HD}$ at the Juntendo University Hospital before and after switching to AFD. Results: MDA-LDL levels divided by LDL cholesterol were significantly lower than those before switching to AFD. Furthermore, levels of plasma pentosidine were lower than those before switching to AFD. Stepwise multiple regression analysis revealed that the percent change of the calcium-phosphorus product in the nondiabetic group and that of phosphorus in the diabetic group were predictive variables for the percent change of MDA-LDL/LDL, whereas the percent change of log high-sensitive C-reactive protein and that of systolic blood pressure in the nondiabetic group and that of diastolic blood
\end{abstract}


pressure in the diabetic group were predictive variables for the percent change of plasma pentosidine. Conclusions: It appears that AFD decreases glycoxidation and lipid peroxidation products when compared with acid citrate dextrose in HD patients. The reduction of oxidative stress by AFD during HD may have possible beneficial effects on atherosclerosis through calciumphosphorus metabolism and blood pressure.

Copyright $\odot 2012$ S. Karger AG, Basel

\section{Introduction}

Previous studies have shown that the presence of high levels of glycoxidation and lipid peroxidation products is associated with atherosclerosis, diabetes mellitus (DM) and aging [1-4]. Increased levels of these products have been well documented in patients with endstage kidney disease (ESKD) [5, 6]. Sakata et al. [7] and Yamamoto et al. [8] demonstrated that glycoxidation and lipid peroxidation may promote the development of vascular complications, particularly atherosclerosis in patients with ESKD. Cardiovascular complications are the principal cause of morbidity and mortality in patients with ESKD who require hemodialysis (HD).

Plasma pentosidine is a major glycoxidation product formed under oxidative conditions. Several studies have demonstrated the increased concentrations of pentosidine in the tissues and plasma of uremic patients [9]. Malondialdehyde-modified low-density lipoprotein (MDA-LDL) is an end product of lipid peroxidation and may be involved in the early stages of atherosclerotic lesion progression. In addition, it is a useful biomarker of atherosclerosis $[10,11]$.

A conventional dialysate, an acetate-containing sodium bicarbonate solution, is currently used for standard HD in Japan. However, acetate-induced adverse effects such as arterial hypotension, depressed left ventricular function and increased incidences of nausea, vomiting and headache have been reported in numerous studies $[12,13]$. Previous studies demonstrated that acetate promotes vascular damage and leads to the aforementioned adverse effects $[12,14]$.

Recently, acetate-free citrate dialysate (AFD) has become available in Japan. The objective of the present study in maintenance HD patients was to evaluate the beneficial effects of AFD on clinical parameters and to determine the attenuating effects of AFD on the glycoxidation and lipid peroxidation products by measuring plasma pentosidine and MDA-LDL levels.

\section{Methods}

\section{Patient Characteristics}

Fifty-nine patients on maintenance HD at the Juntendo University Hospital (39 males and 20 females; mean age $64 \pm 1.7$ years) participated in this study. The hospital ethics committee of the Juntendo University approved the study and informed consent was obtained from the patients enrolled in this study. The baseline characteristics of the patients are summarized in table 1 . Their mean age was $64 \pm 1.7$ years and mean duration of HD therapy was $7.8 \pm 0.8$ years.

\section{Dialysate}

Before the study, acetate-containing dialysate was used in all patients at a flow rate of $500 \mathrm{ml} / \mathrm{min}$ from a central supply system, and then they were switched to AFD (Carbostar ${ }^{\circledR}$, 


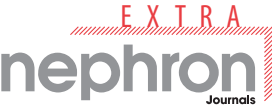

Table 1. Baseline characteristics at the start of the study

\begin{tabular}{l}
\hline \begin{tabular}{l} 
Nephron Extra 2012;2:256-268 \\
\hline DOI: 10.1159/000342258 \\
Published online: September 27, 2012
\end{tabular} \\
\hline
\end{tabular}

Masuda et al.: Effects of Acetate-Free Citrate Dialysate on Glycoxidation and Lipid

Peroxidation Products in Hemodialysis Patients

Age, years

Gender (male/female)

Duration of dialysis, years

Body height, $\mathrm{cm}$

Body weight, $\mathrm{kg}$

Cause of kidney failure, $n$

Glomerulonephritis

Diabetes mellitus

Nephrosclerosis

Polycystic kidney disease

Other
$39 / 20$

$7.8 \pm 0.8$

$160.5 \pm 1.2$

$52.5 \pm 1.5$

16

14

13

5

11

Ajinomoto Pharmaceuticals Co., Ltd., Tokyo, Japan). The composition of AFD was as follows: sodium $140 \mathrm{mEq} / \mathrm{l}$, potassium $2.0 \mathrm{mEq} / \mathrm{l}$, calcium $3.0 \mathrm{mEq} / \mathrm{l}$, magnesium $1.0 \mathrm{mEq} / \mathrm{l}$, chloride $111 \mathrm{mEq} / \mathrm{l}$, bicarbonate $35 \mathrm{mEq} / \mathrm{l}$ and citrate $2.0 \mathrm{mEq} / \mathrm{l}$. Conventional acid citrate dextrose composition was as follows: sodium $143 \mathrm{mEq} / \mathrm{l}$, potassium $2.0 \mathrm{mEq} / \mathrm{l}$, calcium 2.5 $\mathrm{mEq} / \mathrm{l}$, magnesium $1.0 \mathrm{mEq} / \mathrm{l}$, chloride $112 \mathrm{mEq} / \mathrm{l}$, bicarbonate $27.5 \mathrm{mEq} / \mathrm{l}(\mathrm{mmol} / \mathrm{l})$ and acetate $11 \mathrm{mEq} / \mathrm{l}$. With the exception of the amounts of erythropoiesis-stimulating agent and iron supplements, dialysis prescriptions did not change after switching to AFD.

\section{Laboratory Parameters}

Five blood samples were obtained from each patient, i.e. at the start of AFD (baseline) and at 1, 3, 6 and 12 months after switching to AFD. All samples were collected from the arterial line at the start of the HD session at the beginning of the week. Hemoglobin, hematocrit, serum total protein, serum albumin, serum lipids [LDL cholesterol, high-density lipoprotein (HDL) cholesterol, non-HDL cholesterol, and triglyceride] and high-sensitive C-reactive protein (hs-CRP) levels were measured using standard laboratory protocols of the Juntendo University Hospital. Plasma pentosidine and serum MDA-LDL levels were measured using enzyme-linked immunosorbent assays (plasma pentosidine, Fushimi Pharmaceutical, Kagawa, Japan; MDA-LDL, Sekisui Medical Co., Ltd., Tokyo, Japan). MDA-LDL levels divided by LDL cholesterol (MDA-LDL/LDL-C) were calculated as an indicator of the extent of LDL cholesterol oxidation. Moreover, the percent change of each parameter at 12 months after switching to AFD from baseline was calculated. Additionally, all patients were divided into a non-DM (NDM) group or a DM group, and the two groups were compared.

As a validated indicator of subclinical atherosclerosis and arterial stiffness, the measurements of carotid intima media thickness, ankle brachial pressure index and pulse wave velocity were examined at two points, namely, before and after switching to AFD using standard protocols of the Juntendo University Hospital. The measurements for each parameter were averaged to obtain the mean value.

\section{Statistical Analysis}

Data are expressed as means \pm standard deviations. Statistical analyses were performed using Stat View software for Windows. Comparisons between more than two groups of patients were analyzed by one-way ANOVA with Fisher's test. First, correlation of the percent change of plasma pentosidine and MDA-LDL levels with that of other laboratory parameters was determined by single linear univariate analysis. Variables with a $p$ value of $<0.10$ were then analyzed using a stepwise multivariate regression analysis on the basis of a forwardbackward procedure. A logarithmic transformation of hs-CRP and triglyceride was used to 
Masuda et al.: Effects of Acetate-Free Citrate Dialysate on Glycoxidation and Lipid

Peroxidation Products in Hemodialysis Patients

Table 2. Blood pressure parameters

\begin{tabular}{|c|c|c|c|c|c|}
\hline & \multirow[t]{2}{*}{ At start } & \multicolumn{4}{|l|}{ After } \\
\hline & & 1 month & 3 months & 6 months & 12 months \\
\hline \multicolumn{6}{|l|}{ At beginning of dialysis } \\
\hline Systolic BP, mm Hg & $156 \pm 3.5$ & $152 \pm 2.9$ & $157 \pm 2.6$ & $153 \pm 3.3$ & $153 \pm 3.1$ \\
\hline Diastolic BP, mm Hg & $78 \pm 2.1$ & $76 \pm 1.8$ & $78 \pm 1.4$ & $77 \pm 1.7$ & $76 \pm 1.5$ \\
\hline Pulse pressure, mm Hg & $79.4 \pm 2.3$ & $77.7 \pm 2.2$ & $80.0 \pm 2.1$ & $76.6 \pm 2.6$ & $78.3 \pm 2.5$ \\
\hline Mean BP, mm Hg & $104.0 \pm 2.3$ & $101.4 \pm 1.9$ & $104.4 \pm 1.6$ & $102.3 \pm 2.0$ & $102.3 \pm 1.8$ \\
\hline \multicolumn{6}{|l|}{ At completion of dialysis } \\
\hline Systolic BP, mm Hg & $148 \pm 3.3$ & $145 \pm 3.4$ & $145 \pm 3.1$ & $142 \pm 3.0$ & $149 \pm 3.2$ \\
\hline Diastolic BP, mm Hg & $78 \pm 1.7$ & $77 \pm 2.0$ & $77 \pm 1.7$ & $75 \pm 1.6^{*}$ & $75 \pm 1.7$ \\
\hline Pulse pressure, mm Hg & $70.7 \pm 2.6$ & $68.7 \pm 2.4$ & $69.5 \pm 2.4$ & $68.4 \pm 2.6$ & $75.0 \pm 3.0$ \\
\hline Mean BP, mm Hg & $101.9 \pm 1.9$ & $100.0 \pm 2.3$ & $99.9 \pm 1.9$ & $97.5 \pm 1.8^{*}$ & $100.2 \pm 1.7$ \\
\hline
\end{tabular}

$\mathrm{BP}=$ Blood pressure. ${ }^{*} \mathrm{p}<0.05$ vs. at start.

Fig. 1. Change in systolic blood pressure during $\mathrm{HD}$ sessions $[\Delta$ systolic blood pressure $=$ (systolic blood pressure at the completion of HD) - (systolic blood pressure at the start of HD)]. No significant differences were observed during the study.

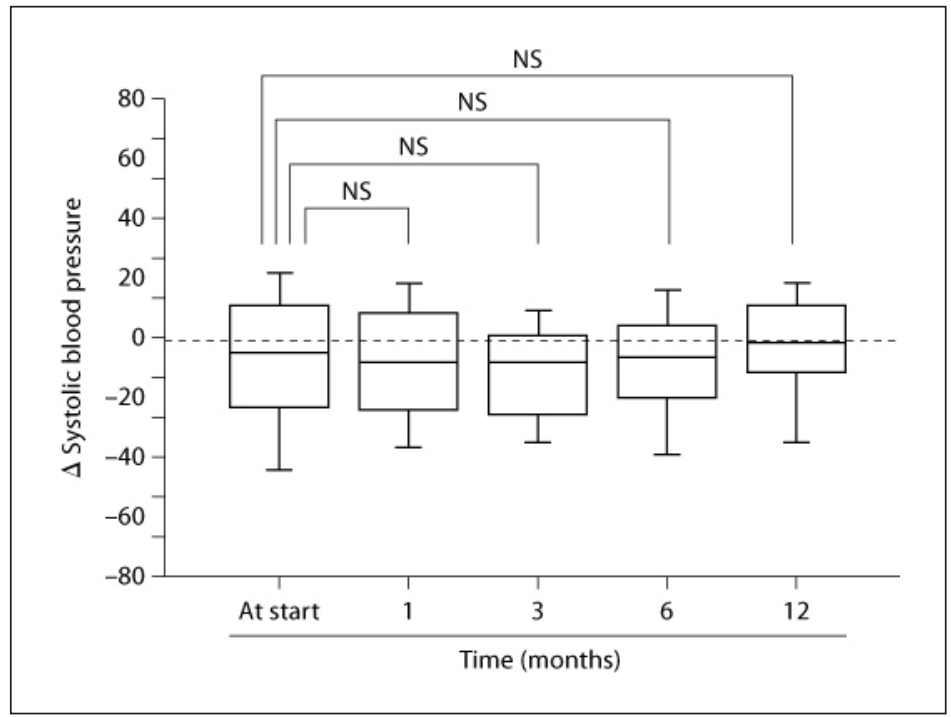

render the normal distribution for parametric tests. The F value for entry or removal of candidate variables from discriminant function was set at 4.0. A p value $<0.05$ was defined as statistically significant.

\section{Results}

\section{Blood Pressure}

The blood pressure data are shown in table 2. There were no significant differences in systolic and diastolic blood pressures, pulse pressure and mean blood pressure at the beginning of the dialysis session and after switching to AFD. Figure 1 shows changes in the systolic blood pressure gap, defined as post-dialysis systolic pressure minus pre-dialysis systolic pressure for a single HD session. There was no statistically significant change in the 
Peroxidation Products in Hemodialysis Patients

Table 3. Biochemical parameters

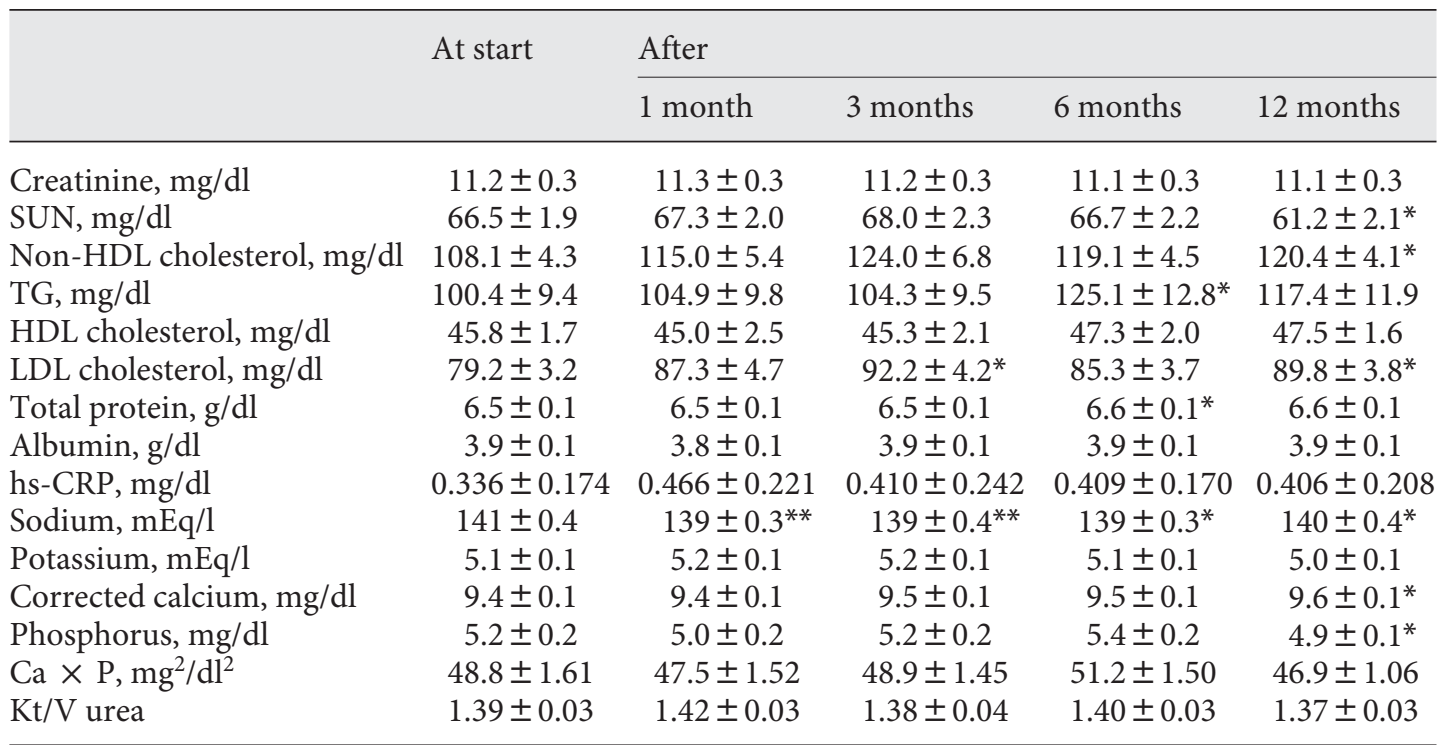

Non-HDL cholesterol, LDL cholesterol and HDL cholesterol were analyzed by the two-sided t test.

SUN = Serum urea nitrogen; $\mathrm{TG}=$ triglyceride.

${ }^{*} \mathrm{p}<0.05$ vs. at start. ${ }^{* *} \mathrm{p}<0.0001$ vs. at start.

levels of the systolic pressure gap after switching to AFD. Moreover, the diastolic blood pressure gap during the HD session did not change with AFD (data not shown).

\section{Biological Parameters}

The biological parameters are listed in table 3. The level of plasma triglyceride at 6 months after switching to AFD was significantly increased from $100.4 \pm 9.4$ to $125.1 \pm 12.8$ $\mathrm{mg} / \mathrm{dl}(\mathrm{p}<0.05)$. However, no significant change was observed at 12 months after switching to AFD. Non-HDL cholesterol level at 12 months after switching to AFD was significantly increased from $108.1 \pm 4.3$ to $120.4 \pm 4.1 \mathrm{mg} / \mathrm{dl}(\mathrm{p}<0.05)$. In addition, LDL cholesterol levels at 3 and 6 months after switching to AFD were significantly increased from $79.2 \pm 3.2$ to $92.2 \pm 4.2 \mathrm{mg} / \mathrm{dl}(\mathrm{p}<0.05)$ and then to $89.3 \pm 3.8 \mathrm{mg} / \mathrm{dl}(\mathrm{p}<0.05)$. Levels of plasma sodium were significantly decreased after switching to AFD (baseline, $141.0 \pm 0.4 \mathrm{mEq} / \mathrm{l} ; 1$ month, $139.0 \pm 0.3 \mathrm{mEq} / \mathrm{l}(\mathrm{p}<0.001) ; 3$ months, $139.0 \pm 0.4 \mathrm{mEq} / \mathrm{l}(\mathrm{p}<0.001) ; 6$ months, $139.0 \pm 0.3 \mathrm{mEq} / \mathrm{l}(\mathrm{p}<0.05)$, and 12 months, $140.0 \pm 0.4 \mathrm{mEq} / \mathrm{l}(\mathrm{p}<0.05)$. The level of serum urea nitrogen at 12 months after switching to AFD was significantly decreased from $66.5 \pm 1.9$ to $61.2 \pm 2.1 \mathrm{mg} / \mathrm{dl}(\mathrm{p}<0.05)$. The levels of corrected calcium were significantly increased and those of phosphorus significantly decreased at 12 months after switching to AFD. There were no significant changes in the levels of serum creatinine, albumin, HDL cholesterol, hs-CRP or potassium levels after switching to AFD. The efficacy of dialysis calculated by Kt/V was evaluated, although no significant change in efficacy after switching to AFD was observed. Compared with NDM patients, DM patients had higher plasma triglyceride but lower hs-CRP at 12 months after switching to AFD, but there were no significant changes in the percent change of each parameter (table 4). 
Masuda et al.: Effects of Acetate-Free Citrate Dialysate on Glycoxidation and Lipid

Peroxidation Products in Hemodialysis Patients

Table 4. Comparison of the characteristics between nondiabetic and diabetic HD patients

\begin{tabular}{|c|c|c|c|c|c|c|c|c|c|}
\hline & \multicolumn{2}{|l|}{ At start } & \multirow[t]{2}{*}{$\mathrm{p}$ value } & \multicolumn{2}{|c|}{ After 12 months } & \multirow[t]{2}{*}{$\mathrm{p}$ value } & \multicolumn{2}{|c|}{$\%$ change from baseline } & \multirow[t]{2}{*}{$\mathrm{p}$ value } \\
\hline & nondiabetic & diabetic & & nondiabetic & diabetic & & nondiabetic & diabetic & \\
\hline MDA-LDL/LDL $(\mathrm{U} \cdot \mathrm{dl} / \mathrm{mg} \cdot \mathrm{l})$ & $1.232 \pm 0.055$ & $1.324 \pm 0.083$ & 0.3997 & $1.005 \pm 0.045$ & $0.980 \pm 0.079$ & 0.7974 & $-11.3 \pm 5.7$ & $-16.7 \pm 9.5$ & 0.6692 \\
\hline Pentosidine, $\mu \mathrm{g} / \mathrm{dl}$ & $0.539 \pm 0.031$ & $0.461 \pm 0.075$ & 0.2620 & $0.369 \pm 0.025$ & $0.300 \pm 0.051$ & 0.2136 & $-29.4 \pm 2.6$ & $17.6 \pm 9.2$ & 0.0913 \\
\hline $\mathrm{TG}, \mathrm{mg} / \mathrm{dl}$ & $98.7 \pm 7.6$ & $116.6 \pm 17.1$ & 0.2805 & $102.2 \pm 9.0$ & $162.7 \pm 25.1$ & 0.0072 & $13.2 \pm 9.2$ & $52.3 \pm 23.9$ & 0.0754 \\
\hline Albumin, g/dl & $3.8 \pm 0.1$ & $4.0 \pm 0.1$ & 0.1125 & $3.9 \pm 0.1$ & $4.1 \pm 0.1$ & 0.0703 & $1.5 \pm 1.1$ & $1.0 \pm 1.5$ & 0.8533 \\
\hline hs-CRP, mg/dl & $0.387 \pm 0.196$ & $0.385 \pm 0.175$ & 0.9965 & $0.480 \pm 0.258$ & $0.097 \pm 0.061$ & 0.4490 & $98.6 \pm 56.2$ & $-19.8 \pm 18.5$ & 0.2851 \\
\hline Corrected calcium, mg/dl & $9.5 \pm 0.1$ & $9.3 \pm 0.1$ & 0.2873 & $9.7 \pm 0.1$ & $9.1 \pm 0.3$ & 0.0134 & $29.2 \pm 10.4$ & $-9.0 \pm 23.1$ & 0.1075 \\
\hline Phosphorus, mg/dl & $5.3 \pm 0.2$ & $5.1 \pm 0.4$ & 0.7594 & $4.9 \pm 0.1$ & $4.7 \pm 0.3$ & 0.4095 & $-2.4 \pm 3.1$ & $-6.2 \pm 6.6$ & 0.5894 \\
\hline $\mathrm{Ca} \times \mathrm{P}, \mathrm{mg}^{2} / \mathrm{dl}^{2}$ & $49.6 \pm 1.7$ & $47.7 \pm 3.2$ & 0.5787 & $47.9 \pm 1.0$ & $43.2 \pm 3.0$ & 0.0703 & $0.6 \pm 3.2$ & $-6.5 \pm 8.1$ & 0.3412 \\
\hline $\mathrm{PH}$ & $7.368 \pm 0.006$ & $7.380 \pm 0.006$ & 0.2788 & $7.371 \pm 0.007$ & $7.376 \pm 0.008$ & 0.7163 & $0.008 \pm 0.075$ & $-0.05 \pm 0.103$ & 0.7030 \\
\hline $\mathrm{HCO}_{3^{-}}, \mathrm{mmol} / \mathrm{l}$ & $22.3 \pm 0.6$ & $22.4 \pm 0.5$ & 0.9056 & $22.4 \pm 0.5$ & $21.8 \pm 0.6$ & 0.5292 & $-0.1 \pm 2.5$ & $-3.6 \pm 3.9$ & 0.4947 \\
\hline Systolic BP, mm Hg & $152.4 \pm 3.4$ & $158.0 \pm 8.3$ & 0.4606 & $151.7 \pm 3.6$ & $158.8 \pm 6.0$ & 0.3449 & $-0.2 \pm 2.3$ & $-0.5 \pm 5.6$ & 0.9616 \\
\hline Diastolic BP, mm Hg & $75.2 \pm 1.9$ & $76.5 \pm 5.8$ & 0.7824 & $74.8 \pm 1.7$ & $79.9 \pm 3.3$ & 0.1601 & $0.1 \pm 2.2$ & $-1.3 \pm 5.2$ & 0.7630 \\
\hline Hemoglobin, g/dl & $10.5 \pm 0.1$ & $10.5 \pm 0.3$ & 0.9927 & $10.6 \pm 0.2$ & $11.2 \pm 0.3$ & 0.1085 & $-0.3 \pm 1.6$ & $5.6 \pm 2.7$ & 0.0846 \\
\hline Hematocrit, \% & $32.8 \pm 0.4$ & $32.4 \pm 1.0$ & 0.5881 & $32.7 \pm 0.5$ & $34.0 \pm 0.9$ & 0.2398 & $-0.6 \pm 1.5$ & $5.9 \pm 3.0$ & 0.0507 \\
\hline IMT, mm & $0.87 \pm 0.03$ & $0.92 \pm 0.05$ & 0.3568 & $0.86 \pm 0.02$ & $0.90 \pm 0.03$ & 0.2755 & $-0.1 \pm 1.9$ & $-0.1 \pm 4.2$ & 0.9904 \\
\hline
\end{tabular}

$\mathrm{TG}=$ Triglyceride; $\mathrm{BP}=$ blood pressure IMT = intima media thickness; $\mathrm{ABI}=$ ankle brachial pressure index; $\mathrm{PWV}=$ pulse wave velocity.

Table 5. Data on arterial blood gas

\begin{tabular}{lclrll}
\hline & At start & After & & \\
\cline { 3 - 5 } & & 1 month & 3 months & 6 months & 12 months \\
\hline $\mathrm{pH}$ & $7.37 \pm 0.01$ & $7.38 \pm 0.01$ & $7.37 \pm 0.01$ & $7.39 \pm 0.00^{*}$ & $7.34 \pm 0.01$ \\
$\mathrm{PCO}_{2}, \mathrm{~mm} \mathrm{Hg}$ & $40.0 \pm 0.8$ & $40.0 \pm 0.5$ & $40.4 \pm 0.6$ & $39.2 \pm 0.5$ & $38.9 \pm 0.6$ \\
$\mathrm{PO}_{2}, \mathrm{~mm} \mathrm{Hg}$ & $101.0 \pm 3.2$ & $99.9 \pm 3.0$ & $106.0 \pm 2.6$ & $103.2 \pm 3.0$ & $94.2 \pm 2.7^{*}$ \\
$\mathrm{HCO}_{3}{ }^{-}, \mathrm{mmol} / 1$ & $22.7 \pm 0.5$ & $22.9 \pm 0.4$ & $23.0 \pm 0.4$ & $23.1 \pm 0.4$ & $22.2 \pm 0.4$ \\
Anion gap & $13.8 \pm 0.5$ & $13.3 \pm 2.7$ & $15.7 \pm 0.4$ & $15.1 \pm 0.5$ & $16.3 \pm 0.5$ \\
\hline
\end{tabular}

${ }^{*} \mathrm{p}<0.05$ vs. at start.

\section{Acidosis}

The $\mathrm{pH}$ level at the beginning of the HD session at 6 months after switching to AFD was significantly increased from $7.372 \pm 0.005$ to $7.387 \pm 0.005(\mathrm{p}<0.05)$. However, there was no significant difference between the $\mathrm{pH}$ levels at baseline and at 12 months (table 5). There was no significant change in bicarbonate levels after switching to AFD. Other parameters also did not change significantly.

\section{Management of Renal Anemia and Metabolism of Iron}

As shown in tables 6 and 7, the new dialysate did not affect the levels of hematocrit, hemoglobin, iron and ferritin, or the dose of recombinant human erythropoietin and iron supplements with the exception of darbepoetin alfa dosage, which was increased from 80.0 \pm 15.1 to $101.7 \pm 17.8 \mathrm{U} /$ month and then to $113.9 \pm 19.7 \mathrm{U} /$ month at 6 and 12 months after switching to AFD. The total iron binding capacity at 6 months after switching to AFD was increased from $252 \pm 6.5$ to $264 \pm 6.3 \mu \mathrm{g} / \mathrm{dl}$. 


\begin{tabular}{l}
\hline Nephron Extra 2012;2:256-268 \\
\hline $\begin{array}{l}\text { DOI: } 10.1159 / 000342258 \\
\text { Published online: September 27, } 2012\end{array}$ \\
\hline
\end{tabular}

Masuda et al.: Effects of Acetate-Free Citrate Dialysate on Glycoxidation and Lipid

Peroxidation Products in Hemodialysis Patients

Table 6. Parameters assessing hemoglobin, hematocrit and iron stores

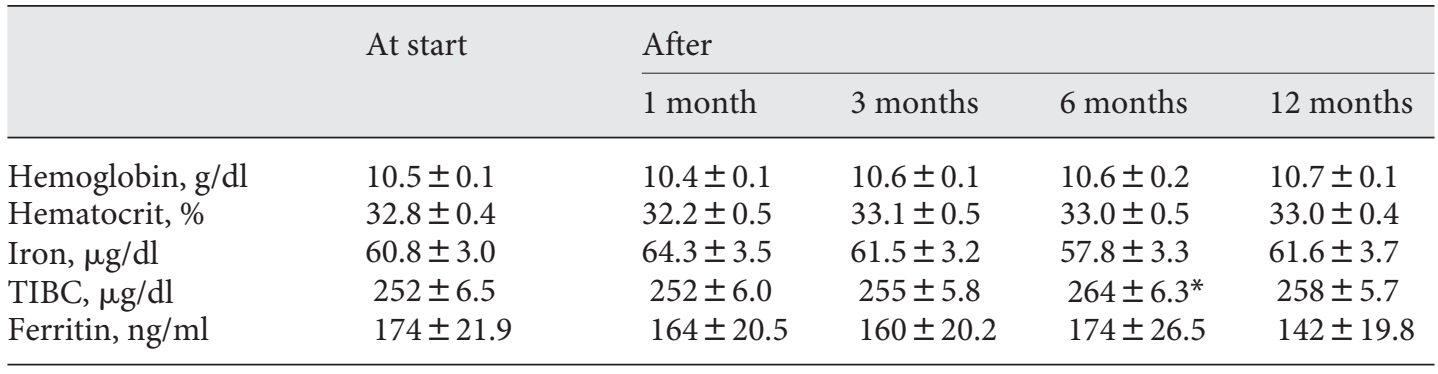

${ }^{*} \mathrm{p}<0.05$ vs. at start. TIBC $=$ Total iron-binding capacity.

Table 7. Data on erythropoiesis-stimulating agents and intravenous iron supplement dosage

\begin{tabular}{lccccc}
\hline & At start & After & & & \\
\cline { 3 - 6 } & & 1 month & 3 months & 6 months & 12 months \\
\hline rHuEPO dosage, U/month & $18,666 \pm 4,494$ & $19,000 \pm 4,416$ & $20,000 \pm 3,708$ & $24,000 \pm 3,969$ & $23,111 \pm 4,712$ \\
Darbepoetin alfa dosage, U/month & $80.0 \pm 15.1$ & $88.3 \pm 18.1$ & $86.4 \pm 16.3$ & $101.7 \pm 17.8^{*}$ & $113.9 \pm 19.7^{*}$ \\
Iron supplement dosage, mg/month & $60.0 \pm 11.3$ & $43.3 \pm 10.4$ & $56.7 \pm 11.2$ & $36.7 \pm 10.9$ & $36.7 \pm 9.8$ \\
\hline
\end{tabular}

Three patients did not take any erythropoiesis-stimulating agents (other patients took rHuEPO or darbepoetin alfa). $\mathrm{rHuEPO}=$ Recombinant human erythropoietin.

${ }^{*} \mathrm{p}<0.05$ vs. at start.

\section{Markers of Glycoxidation and Lipid Peroxidation Products}

Plasma pentosidine levels at 3, 6 and 12 months after switching to AFD were significantly decreased from $0.505 \pm 0.031$ to $0.415 \pm 0.026 \mu \mathrm{g} / \mathrm{ml}(\mathrm{p}<0.0001)$, to $0.449 \pm 0.028$ $\mu \mathrm{g} / \mathrm{ml}(\mathrm{p}<0.0001)$ and then to $0.358 \pm 0.023 \mu \mathrm{g} / \mathrm{ml}(\mathrm{p}<0.0001)$ (fig. 2). Furthermore, MDA-LDL/LDL-C levels at 6 and 12 months after switching to AFD were significantly decreased from $1.254 \pm 0.046$ to $1.075 \pm 0.065 \mathrm{U} \cdot \mathrm{dl} / \mathrm{mg} \cdot 1(\mathrm{p}<0.05)$ and then to $1.000 \pm$ $0.039 \mathrm{U} \cdot \mathrm{dl} / \mathrm{mg} \cdot 1$ ( $\mathrm{p}<0.0001)$ (fig. 3).

Correlation between Glycoxidation or Lipid Peroxidation Products and Each Parameter

Single linear univariate analysis (table 8) showed that the percent change of MDA-LDL/ LDL was correlated positively with that of phosphorus $(\mathrm{r}=0.339, \mathrm{p}=0.0401)$ and the calciumphosphorus product $(\mathrm{Ca} \times \mathrm{P} ; \mathrm{r}=0.336, \mathrm{p}=0.0261)$. The percent change of plasma pentosidine was correlated negatively with that of $\log$ hs-CRP $(r=-0.351, p=0.0359)$ and positively with that of systolic blood pressure $(r=0.390, p=0.0186)$ in the nondiabetic group. In the diabetic group, the percent change of MDA-LDL/LDL was correlated positively with that of phosphorus $(\mathrm{r}=0.663, \mathrm{p}=0.0516)$ and $\mathrm{Ca} \times \mathrm{P}(\mathrm{r}=0.640, \mathrm{p}=0.0637)$. The percent change of plasma pentosidine was correlated negatively with that of systolic blood pressure $(\mathrm{r}=$ $-0.597, \mathrm{p}=0.0687)$ and diastolic blood pressure $(\mathrm{r}=-0.7171, \mathrm{p}=0.0197)$. Stepwise multiple regression analysis revealed that the percent change of $\mathrm{Ca} \times \mathrm{P}$ in the nondiabetic group and that of phosphorus in the diabetic group were predictive variables for the percent change of MDA-LDL/LDL, whereas the percent change of log hs-CRP and that of systolic blood pressure in the nondiabetic group and that of diastolic blood pressure in the diabetic group were predictive variables for the percent change of plasma pentosidine (table 9). 
Fig. 2. Plasma pentosidine levels

Masuda et al.: Effects of Acetate-Free Citrate Dialysate on Glycoxidation and Lipid

Peroxidation Products in Hemodialysis Patients

decreased significantly from $0.505 \pm 0.031$ to $0.415 \pm 0.026$ $\mu \mathrm{g} / \mathrm{ml}$ at 3 months, $0.449 \pm$ $0.028 \mu \mathrm{g} / \mathrm{ml}$ at 6 months, and $0.358 \pm 0.023 \mu \mathrm{g} / \mathrm{ml}$ at 12 months. NS = Not significant.

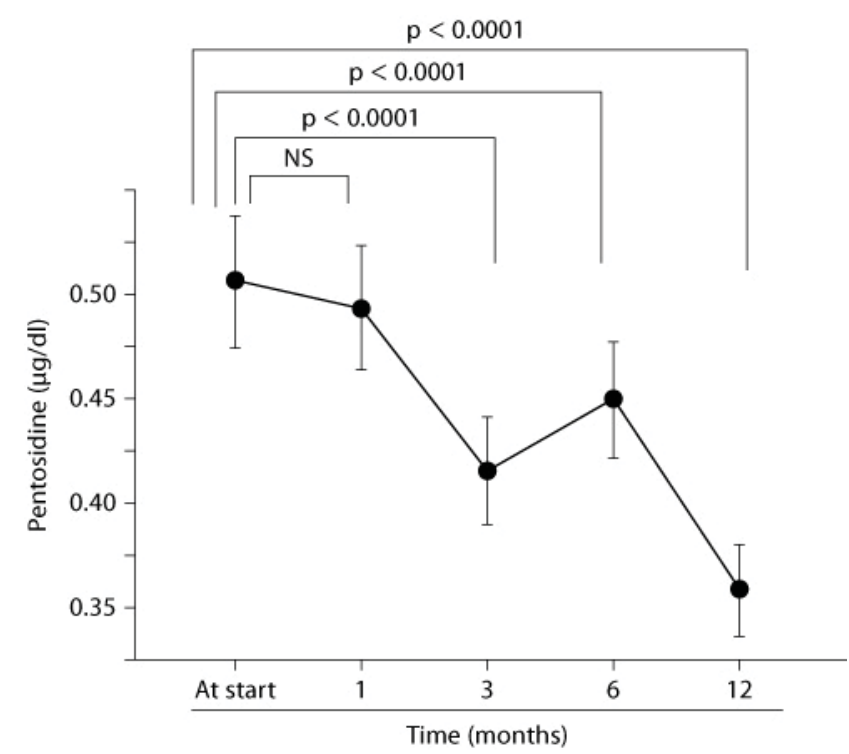

Fig. 3. Serum MDA-LDL/LDL$C$ levels decreased significantly from $1.254 \pm 0.046$ to $1.075 \pm$ $0.065 \mathrm{U} \cdot \mathrm{dl} / \mathrm{mg} \cdot 1(48.5 \pm 1.78$ to $41.6 \pm 2.51 \mathrm{U} / \mathrm{mmol}$ ) at 6 months and then to $1.000 \pm 0.039 \mathrm{U} \cdot \mathrm{dl} /$ $\mathrm{mg} \cdot 1(38.7 \pm 1.51 \mathrm{U} / \mathrm{mmol})$ at 12 months. NS = Not significant.

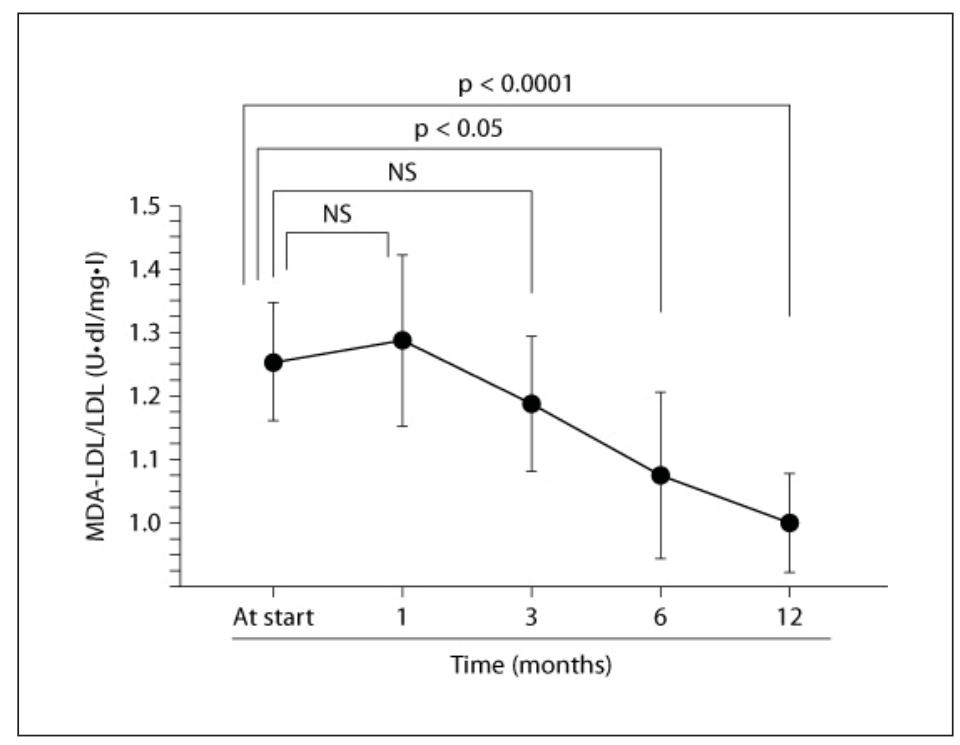

\section{Discussion}

In this study, we clarified the clinical effects of the removal of acetate from dialysate using an AFD that was developed in Japan. Until recently, acetates have been used for many years as buffer in conventional dialysates. However, it is well known that acetates lead to acetate intolerance such as arterial hypotension, nausea, vomiting, headache and decreased left ventricular function [15]. Furthermore, Stenvinkel et al. [16] reported that HD patients often experience malnutrition, inflammation, atherosclerosis (MIA syndrome) and increased oxidative stress. 
Peroxidation Products in Hemodialysis Patients

Table 8. Single univariate linear correlation of percent change of factors associated with percent change of MDA-LDL/LDL-C and pentosidine levels in nondiabetic and diabetic groups

\begin{tabular}{|c|c|c|c|c|c|c|c|c|}
\hline & \multicolumn{4}{|c|}{ Nondiabetic } & \multicolumn{4}{|c|}{ Diabetic } \\
\hline & \multicolumn{2}{|c|}{ MDA-LDL/LDL-C } & \multicolumn{2}{|c|}{ pentosidine } & \multicolumn{2}{|c|}{ MDA-LDL/LDL-C } & \multicolumn{2}{|c|}{ pentosidine } \\
\hline & $\mathrm{r}$ & $\mathrm{p}$ value & $\mathrm{r}$ & $\mathrm{p}$ value & $\mathrm{r}$ & $\mathrm{p}$ value & $\mathrm{r}$ & $\mathrm{p}$ value \\
\hline $\log \mathrm{TG}$ & -0.151 & 0.3711 & 0.140 & 0.4139 & -0.011 & 0.9778 & -0.348 & 0.3244 \\
\hline Albumin & 0.155 & 0.3587 & 0.183 & 0.2849 & 0.509 & 0.1614 & -0.051 & 0.8894 \\
\hline $\log$ hs-CRP & 0.067 & 0.6926 & -0.351 & 0.0359 & 0.295 & 0.4413 & -0.478 & 0.1625 \\
\hline Corrected calcium & 0.045 & 0.7893 & -0.034 & 0.8452 & 0.236 & 0.5405 & -0.199 & 0.5818 \\
\hline Phosphorus & 0.339 & 0.0401 & -0.020 & 0.9101 & 0.663 & 0.0516 & 0.256 & 0.4754 \\
\hline $\mathrm{Ca} \times \mathrm{P}$ & 0.336 & 0.0261 & -0.026 & 0.8808 & 0.640 & 0.0637 & 0.165 & 0.6479 \\
\hline $\mathrm{PH}$ & -0.057 & 0.7469 & 0.064 & 0.7193 & -0.067 & 0.8642 & -0.229 & 0.5249 \\
\hline $\mathrm{HCO}_{3}^{-}$ & -0.059 & 0.7341 & -0.055 & 0.7531 & -0.149 & 0.7014 & 0.113 & 0.7556 \\
\hline Systolic BP & 0.161 & 0.3421 & 0.390 & 0.0186 & 0.134 & 0.7308 & -0.597 & 0.0687 \\
\hline Diastolic BP & 0.107 & 0.5362 & -0.013 & 0.9390 & -0.171 & 0.6609 & -0.717 & 0.0197 \\
\hline Hemoglobin & -0.246 & 0.1428 & 0.012 & 0.7772 & -0.249 & 0.5185 & -0.377 & 0.2825 \\
\hline Hematocrit & -0.223 & 0.1849 & 0.012 & 0.9448 & -0.360 & 0.3411 & -0.443 & 0.2001 \\
\hline IMT & -0.038 & 0.8356 & 0.032 & 0.8639 & -0.326 & 0.3926 & 0.120 & 0.7415 \\
\hline PWV & 0.201 & 0.3060 & 0.057 & 0.7758 & 0.552 & 0.1986 & -0.419 & 0.3017 \\
\hline $\mathrm{ABI}$ & 0.164 & 0.4125 & 0.265 & 0.1903 & 0.407 & 0.3653 & -0.188 & 0.6550 \\
\hline
\end{tabular}

$\mathrm{BP}=$ Blood pressure; $\mathrm{TG}=$ triglyceride

Table 9. Stepwise multiple regression analysis of factors associated with percent change of MDA-LDL/LDL and pentosidine in nondiabetic and diabetic groups

\begin{tabular}{lrl}
\hline & B values & F values \\
\hline $\begin{array}{l}\text { Nondiabetic } \\
\text { MDA-LDA/LDL }\end{array}$ & \\
$\quad$ Phosphorus & & \\
$\quad$ Ca $\times$ P & 0.021 & 0.015 \\
Pentosidine & 0.366 & 5.398 \\
$\quad$ log hs-CRP & -0.353 & 5.677 \\
$\quad$ Systolic BP & 0.392 & 7.015 \\
\hline Diabetic & & \\
MDA-LDA/LDL & & \\
$\quad$ Phosphorus & 0.663 & 5.489 \\
$\quad$ Ca $\times$ P & -0.013 & 0.001 \\
Pentosidine & & 8.455 \\
$\quad$ Diastolic BP & -0.717 & 0.15 \\
$\quad$ Systolic BP & 0.145 & \\
\hline$\quad$ BP = Blood pressure. & & \\
\hline
\end{tabular}

This study demonstrated the suppressive effects of AFD on glycoxidation and lipid peroxidation products in HD patients. Acetate is considered to be one of the bioincompatible factors along with the purity and quality of the dialysis solutions or dialysis membrane type. Use of this bioincompatible dialysis system results in the increased production of free radical or reactive oxygen species (ROS). Todeschini et al. [17] reported limited elevation in superoxide production by neutrophils during acetate-free biofiltration compared to bicarbonate 
Masuda et al.: Effects of Acetate-Free Citrate Dialysate on Glycoxidation and Lipid

Peroxidation Products in Hemodialysis Patients

dialysis. Carozzi et al. [18] reported that acetate may induce monocyte activation and cytokine production. Furthermore, Higuchi et al. [19] reported that cytokine production was minimal during acetate-free biofiltration. In view of these findings, we hypothesize that absence of acetate may contribute to the decreases in plasma pentosidine and MDA-LDL/LDL which are indicators of glycoxidation and lipid peroxidation products in the presence of oxidative stress.

Our results indicate that AFD reduced the production of oxygen free radicals and inflammatory cytokines, which in turn contributed to a possible improvement in the progression of atherosclerosis. Various studies have reported that the increases in oxidative stress and microinflammation are associated with increased atherosclerosis, cardiovascular morbidity and mortality [20-22]. Zhou et al. [23] reported that serum pentosidine was associated with arterial stiffness in HD patients. Generally, DM is characterized by higher levels of oxidative stress. The existence of increased oxidative stress is based on decreased antioxidant capacity in DM along with chronic exposure to increased levels of ROS and increased glycoxidation and peroxidation. Nevertheless, plasma pentosidine, MDA-LDL/LDL levels and other laboratory parameters were not significantly changed in patients with or without DM in this study. Previous studies demonstrated similar results in that no significant difference was found in serum pentosidine level, a marker of glycoxidation, in ESKD patients with or without DM [24]. We consider that diabetic patients receiving HD are consistently exposed to not only hyperglycemia but also uremic status, malnutrition, micro-inflammation and aging which causes oxidative stress in comparison to diabetic patients without renal complications.

By the stepwise multiple regression analysis (table 9), our study demonstrated a correlation between the percent change of plasma pentosidine and that of blood pressure and hs$\mathrm{CRP}$, and between the percent change of MDA-LDL/LDL and that of calcium-phosphorus metabolism in patients with or without DM. Several studies have described the relationship between elevation of calcium-phosphorus metabolism and vascular calcification or highmortality risk in ESKD patients [25-27]. Dalfino et al. [28] reported that oxidative stress could increase the secretion of bone morphogenetic protein-2, a member of the transforming growth factor- $\beta$ superfamily. Furthermore, they showed that increase in bone morphogenetic protein-2 had a direct effect on vascular smooth muscle cells and regulated vascular calcification through increased phosphorus uptake. Another study demonstrated that elevation of phosphorus levels causes endothelial dysfunction and inhibition of nitric oxide (NO) production. This occurred through increased ROS production and endothelial NO synthase inactivation via protein kinase $C$, resulting in impaired endothelium-dependent vasodilation [29]. Thus, our result shows that the reduction of oxidative stress by AFD during HD may have possible beneficial effects on atherosclerosis through calcium-phosphorus metabolism and blood pressure.

Moreover, we investigated data of carotid intima media thickness, pulse wave velocity and ankle brachial pressure index, as indicators of atherosclerosis and arterial stiffness but no significant differences were observed. This may be due to a short 12-month study period and to the fact that such long-term observation is required to examine the effects on atherosclerosis and subsequent mortality.

Blood analysis showed that the $\mathrm{pH}$, bicarbonate and anion gap levels were similar before and after switching to AFD. This finding indicates that acetate-free citrate-buffered dialysis fluids correct metabolic acidosis safely following proper replacement of the acetate-containing dialysate. Biochemical parameters such as corrected calcium increased significantly, and phosphorus levels decreased significantly at 12 months after replacement with AFD. In this study, the new dialysate concentration of calcium was increased from 2.5 to $3.0 \mathrm{mEq} / \mathrm{l}$, and this change is considered reasonable and appropriate. No other obvious side effects or adverse events were observed with switching to AFD. 
We observed no significant differences in the intradialytic blood pressure measured throughout the study. However, several reports showed that acetate-free renal replacement therapy had beneficial effects on intradialytic hypotension compared with acetate-containing therapies [30,31]. Acetates may induce the production of cytokines and NO, a vasodilator that can cause intradialytic cardiovascular instability $[12,30]$. Possible reasons for the different finding may be that there were few previous episodes of intradialytic hypotension, and blood pressure was well-controlled in our patient group. Alternatively, it is possible that our data may have been influenced by factors other than dialysate composition, such as administration of anti-hypertensive drugs, differences in dry weight or seasonal variations. It was therefore difficult to objectively interpret our findings.

Beneficial effects of AFD on anemia associated with renal replacement therapy have been reported in several studies [31,32]. However, our data provides conflicting results from previous reports, since the erythropoiesis-stimulating agent requirement tended to rise, while the intravenous dosage of iron supplement decreased. It was proposed that beneficial effects of AFD on anemia were attributable to the addition of citrate, which has a local anticoagulation effect that inhibits clotting. Maintenance of an effective membrane surface area throughout dialysis may lead to an increase in dialysis efficacy [33]. Other reasons why acetates cause oxidative stress and micro-inflammation, which induces malnutrition and anemia, have also been reported [32]. The precise reasons for the discrepancy between our results and those of earlier studies are unknown. In this study, the type of dialyser, duration of dialysis, dialysate and blood flow remained unchanged throughout the study. The baseline state of anemia was well-controlled in our study group, but it is possible that potential iron deficiency may have affected our results.

Limitations of this study were that the investigation was single arm and not randomized. The treatment duration was relatively short. Furthermore, the majority of participant conditions were well-controlled in terms of anemia, nutrition status, blood pressure and balance of body fluids. A multi-center, randomized trial should be considered in the future.

It appears that HD treatment with AFD decreases glycoxidation and lipid peroxidation products compared with conventional acetate-containing dialysate. The reduction of oxidative stress by AFD during HD may have possible beneficial effects on atherosclerosis through calcium-phosphorus metabolism or blood pressure.

\section{Acknowledgement}

We thank the staff of the hemodialysis center of the Juntendo University Hospital, including Mr. T. Hasegawa, Mr. T. Urita, Ms. R. Fujinami, Ms. S. Takagi, Mr. H. Fukurai, Mr. Y. Sakagen, Mrs. T. Takahashi, Mrs. M. Kato, Ms. T. Araki, Mrs. M. Hamada, Ms. C. Hirai, Ms. A. Hisamura, Ms. K. Sugimoto and Ms. S. Tomimoto for their skillful technical support.

\section{References}

1 Bierhaus A, Hofmann MA, Ziegler R, Nawroth PP: AGEs and their interaction with AGE-receptors in vascular disease and diabetes mellitus. I. The AGE concept. Cardiovasc Res 1998;37:586-600.

-2 Baynes JW: Role of oxidative stress in development of complications in diabetes. Diabetes 1991;40: 405-412.

-3 Schleicher ED, Wagner E, Nerlich AG: Increased accumulation of the glycoxidation product N (epsilon)-(carboxymethyl) lysine in human tissues in diabetes and aging. J Clin Invest 1997;99:457468. 
Masuda et al.: Effects of Acetate-Free Citrate Dialysate on Glycoxidation and Lipid

Peroxidation Products in Hemodialysis Patients

-4 Gohda T, Tanimoto M, Moon JY, Gotoh H, Aoki T, Matsumoto M, Shibata T, Ohsawa I, Funabiki K, Tomino Y: Increased serum endogenous secretory receptor for advanced glycation end-product (esRAGE) levels in type 2 diabetic patients with decreased renal function. Diabetes Res Clin Pract 2008;81:196-201.

-5 Mune M, Yukawa S, Kishino M, Otani H, Kimura K, Nishikawa O, Takahashi T, Kodama N, Saika Y, Yamada Y: Effect of vitamin E on lipid metabolism and atherosclerosis in ESRD patients. Kidney Int 1999;56(suppl 71):S126-S129.

-6 Meng J, Sakata N, Takebayashi S: Increased glycoxidation and lipoperoxidation in the collagen of the myocardium in hemodialysis patients. Cardiovasc Res 2000;47:306-313.

-7 Sakata N, Uesugi N, Takebayashi S, Nagai R, Jono T, Horiuchi S, Takeya M, Itabe H, Takano T, Myint T, Taniguchi N: Glycoxidation and lipid peroxidation of low-density lipoprotein can synergistically enhance atherogenesis. Cardiovasc Res 2001;49:466-475.

-8 Yamamoto Y, Sakata N, Meng J, Sakamoto M, Noma A, Maeda I, Okamoto K, Takebayashi S: Possible involvement of increased glycoxidation and lipid peroxidation of elastin in atherogenesis in haemodialysis patients. Nephrol Dial Transplant 2002;17:630-636.

-9 Sell DR, Monnier VM: End-stage renal disease and diabetes catalyze the formation of a pentose-derived crosslink from aging human collagen. J Clin Invest 1990;85:380-384.

- 10 Kato R, Mori C, Kitazato K, Arata S, Obama T, Mori M, Takahashi K, Aiuchi T, Takano T, Itabe H: Transient increase in plasma oxidized LDL during the progression of atherosclerosis in apolipoprotein E knockout mice. Arterioscler Thromb Vasc Biol 2009;29:33-39.

-11 Requena JR, Fu MX, Ahmed MU, Jenkins AJ, Lyons TJ, Thorpe SR: Lipoxidation products as biomarkers of oxidative damage to proteins during lipid peroxidation reactions. Nephrol Dial Transplant 1996;11(suppl 5):48-53.

-12 Amore A, Cirina P, Mitola S, Peruzzi L, Bonaudo R, Gianoglio B, Coppo R: Acetate intolerance is mediated by enhanced synthesis of nitric oxide by endothelial cells. J Am Soc Nephrol 1997;8:14311436.

$\checkmark 13$ Jacob AD, Elkins N, Reiss OK, Chan L, Shapiro JI: Effects of acetate on energy metabolism and function in the isolated perfused rat heart. Kidney Int 1997;52:755-760.

- 14 Amore A, Cirina P, Bonaudo R, Conti G, Chiesa M, Coppo R: Bicarbonate dialysis, unlike acetatefree biofiltration, triggers mediators of inflammation and apoptosis in endothelial and smooth muscle cells. J Nephrol 2006;19:57-64.

15 Novello A, Kelsch RC, Easterling RE: Acetate intolerance during hemodialysis. Clin Nephrol 1976;5: 29-32.

-16 Stenvinkel P, Heimbürger O, Paultre F, Diczfalusy U, Wang T, Berglund L, Jogestrand T: Strong association between malnutrition, inflammation, and atherosclerosis in chronic renal failure. Kidney Int 1999;55:1899-1911.

- 17 Todeschini M, Macconi D, Fernández NG, Ghilardi M, Anabaya A, Binda E, Morigi M, Cattaneo D, Perticucci E, Remuzzi G, Noris M: Effect of acetate-free biofiltration and bicarbonate hemodialysis on neutrophil activation. Am J Kidney Dis 2002;40:783-793.

-18 Carozzi S, Nasini MG, Caviglia PM, Schelotto C, Santoni O, Atti M: Acetate free biofiltration. Effects on peripheral blood monocyte activation and cytokine release. ASAIO J 1992;38:52-54.

- 19 Higuchi T, Yamamoto C, Kuno T, Okada K, Soma M, Fukuda N, Nagura Y, Takahashi S, Matsumoto $\mathrm{K}$ : A comparison of bicarbonate hemodialysis, hemodiafiltration, and acetate-free biofiltration on cytokine production. Ther Apher Dial 2004;8:460-467.

20 Dursun E, Ozben T, Süleymanlar G, Dursun B, Yakupoglu G: Effect of hemodialysis on the oxidative stress and antioxidants. Clin Chem Lab Med 2002;40:1009-1013.

-21 Bonnefont-Rousselot D, Bastard JP, Jaudon MC, Delattre J: Consequences of the diabetic status on the oxidant/antioxidant balance. Diabetes Metab 2000;26:163-176.

22 Himmelfarb J, Stenvinkel P, Ikizler TA, Hakim RM: The elephant in uremia: oxidant stress as a unifying concept of cardiovascular disease in uremia. Kidney Int 2002;62:1524-1538.

-23 Zhou Y, Yu Z, Jia H, Sun F, Ma L, Guo R, Peng L, Cui T: Association of serum pentosidine with arterial stiffness in hemodialysis patients. Artif Organs 2010;34:193-199.

-24 Suliman ME, Heimbürger O, Bárány P, Anderstam B, Pecoits-Filho R, Rodríguez Ayala E, Qureshi AR, Fehrman-Ekholm I, Lindholm B, Stenvinkel P: Plasma pentosidine is associated with inflammation and malnutrition in end-stage renal disease patients starting on dialysis therapy. J Am Soc Nephrol 2003;14:1614-1622. 
-25 Ahmed S, O’Neill KD, Hood AF, Evan AP, Moe SM: Calciphylaxis is associated with hyperphosphatemia and increased osteopontin expression by vascular smooth muscle cells. Am J Kidney Dis 2001; 37:1267-1276.

-26 Goodman WG, Goldin J, Kuizon BD, Yoon C, Gales B, Sider D, Wang Y, Chung J, Emerick A, Greaser L, Elashoff RM, Salusky IB: Coronary-artery calcification in young adults with end-stage renal disease who are undergoing dialysis. N Engl J Med 2000;342:1478-1483.

-27 Block GA, Hulbert-Shearon TE, Levin NW, Port FK: Association of serum phosphorus and calcium $\times$ phosphate product with mortality risk in chronic hemodialysis patients: a national study. Am J Kidney Dis 1998;31:607-617.

- 28 Dalfino G, Simone S, Porreca S, Cosola C, Balestra C, Manno C, Schena FP, Grandaliano G, Pertosa G: Bone morphogenetic protein-2 may represent the molecular link between oxidative stress and vascular stiffness in chronic kidney disease. Atherosclerosis 2010;211:418-423.

-29 Shuto E, Taketani Y, Tanaka R, Harada N, Isshiki M, Sato M, Nashiki K, Amo K, Yamamoto H, Higashi Y, Nakaya Y, Takeda E: Dietary phosphorus acutely impairs endothelial function. J Am Soc Nephrol 2009;20:1504-1512.

-30 Noris M, Todeschini M, Casiraghi F, Roccatello D, Martina G, Minetti L, Imberti B, Gaspari F, Atti M, Remuzzi G: Effect of acetate, bicarbonate dialysis, and acetate-free biofiltration on nitric oxide synthesis: implications for dialysis hypotension. Am J Kidney Dis 1998;32:115-124.

- 31 Sato T, Taoka M, Miyahara T: Improvement of autonomic nervous regulation by blood purification therapy using acetate-free dialysis fluid - clinical evaluation by laser Doppler flowmetry. Contrib Nephrol 2011;168:195-203.

- 32 Eiselt J, Racek J, Opatrny K Jr: The effect of hemodialysis and acetate-free biofiltration on anemia. Int J Artif Organs 2000;23:173-180.

33 Kossmann RJ, Gonzales A, Callan R, Ahmad S: Increased efficiency of hemodialysis with citrate di-alysate: a prospective controlled study. Clin J Am Soc Nephrol 2009;4:1459-1464. 